\title{
Luksasio patela pada kambing
}

\author{
Fauzan Arisandi ${ }^{1}$, Igan Arpan E Putra ${ }^{1}$, Zulfikar H Islami ${ }^{1, \dagger}$, Dwi U Rahmiati ${ }^{2, *}$, \\ Budhy J Widyananta ${ }^{2}$
}

${ }^{1}$ Program Pendidikan Profesi Dokter Hewan, Fakultas Kedokteran Hewan, Institut Pertanian Bogor, Bogor

${ }^{2}$ Departemen Klinik Reproduksi dan Patologi, Fakultas Kedokteran Hewan, Institut Pertanian Bogor, Bogor

\begin{abstract}
Luksasio persendian patela merupakan kondisi bawaan di mana tulang tempurung lutut (patela) mengalami dislokasi dari alur troklearis normal. Luksasio ini secara klinis dapat terjadi pada bagian medial, di dalam permukaan, lateral, maupun di luar permukaan lutut. Tulisan ini melaporkan kasus patela berpindah lokasi pada kambing. Tulang patela berpindah ke medial persendian lutut dan terlihat berada di belakang tulang femur, sehingga persendian lutut tidak dapat bergerak. Tindakan pembedahan dilakukan untuk melakukan reposisi. Insisi dimulai dari daerah parapatelar sekitar $1 \mathrm{~cm}$ dibagian lateral patela dan di atas sendi lutut. Jaringan sendi dipreparir dan dieksplorasi sehingga daerah femoro-tibia dapat diakses dengan baik. Inspeksi dan konfirmasi keadaan ligamen krusiate dari lutut dilakukan untuk melihat keparahan luksasio. Terdapat dua kelainan yang terjadi, yaitu troklea ossis femoris dangkal dan beberapa ligamen patela yang memendek karena kejadian dislokasi telah berlangsung kronis. Tindakan yang dilakukan adalah memperdalam cekungan pada troklea ossis femoris menggunakan kikir sebagai tempat pertautan patela. Selanjutnya melakukan pemotongan tendon (ligamen patela lateral) dan mereposisi patela. Berdasarkan citra radiografi menampakkan tulang patela berada di kranial tulang femur sehingga persendian lutut dapat bergerak dengan baik.
\end{abstract}

Keywords:

ligamen patela lateral, luksasio patela, troklea ossis femoris

\section{- PENDAHULUAN}

Luksasio persendian patela merupakan kondisi bawaan di mana tempurung lutut (patela) mengalami dislokasi dari alur troklear (Harasen 2006a). Terdapat berbagai tingkatan luksasio patela yang dinilai berdasarkan pemeriksaan fisik (Harasen 2006a). Grade 0, merupakan kondisi normal; grade 1 yaitu kejadian luksasio patela yang terjadi saat pemberikan tekanan dan kembali keposisi semula ketika tekanan dihentikan; grade 2 yaitu luksasio yang terjadi saat pemberian tekanan dan memungkinkan untuk kembali terjadi luksasio setelah tekanan dihentikan; grade 3 luksasio yang terjadi spontan dan dapat kembali dengan sendirinya pada pada sulkus patela; grade 4 yaitu luksasio yang terjadi sepanjang waktu dan tidak dpaat kembali pada posisi semula. Perpindahan abnormal dari tempurung lutut dapat mengakibatkan penyakit degeneratif sendi dan tulang rawan, nyeri dan kepincangan (Johnson 2001). Berbagai tingkat keparahan luksasio dapat terjadi dan mungkin diperlukan tindakan bedah untuk penanganan.

\section{- BAHAN DAN METODE}

Kaki kambing diperiksa melalui pengambilan gambar x-ray. Gambar diambil pada regio ekstremitas kaki belakang dengan $\mathrm{kVp}$ sebesar 64 dan mAs 1. Posisi pengambilan gambar melintang dari arah medial (Gambar 1a). Setelah tindakan bedah dilakukan pengambilan gambar x-ray untuk melihat hasil sebagaimana pada Gambar 1b.
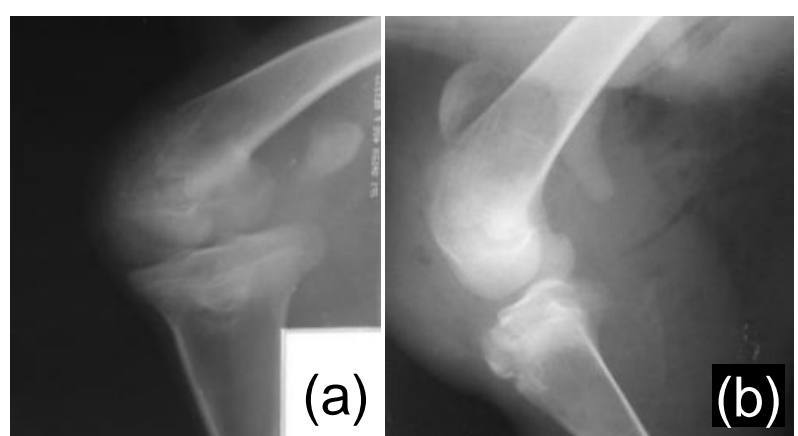

Gambar 1 Radiografi kaki kambing yang mengalami luksasio tulang patela. (a) Tulang patela yang mengalami luksasio (sebelum tindakan bedah) dan (b) pascabedah.

Tindakan pembedahan dilakukan dengan menginsisi daerah parapatelar sekitar $1 \mathrm{~cm}$ dibagian lateral patela dan di atas sendi lutut (Gambar 2a), lalu diperpanjang dari proksimal patela sampai tuberositas tibia. Fasia subkutan dikuakkan sampai ligamen patela sehingga tuberositas tibia terlihat (Gambar 2b). Tulang tibia difleksorkan dan diputar ke bagian medial agar ruang persendian terlihat jelas. Retinakulum disayat kurang lebih $1 \mathrm{~cm}$ di lateral tulang patela. Lapisan sinovial dipisahkan dengan sayatan

Diterima: 01-07-2018 | Direvisi: 01-08-2018 | Disetujui: 05-08-2018 (C) 2018 CC-BY-SA. Ini adalah artikel Open Access yang didistribusikan berdasarkan ketentuan dari Creative Commons Attribution ShareAlike 4.0 International License (https://creativecommons.org/licenses/by-sa/4.0/). 
memanjang dari bagian proksimal tulang patela. Kapsula persendian disayat dari bagian proksimal tulang patela hingga mendekati vastus distalis lateralis. Inspeksi dan konfirmasi untuk melihat keadaan ligamen cruciate dari lutut. Berdasarkan hasil inspeksi, troklea pertulangan femoris dangkal, dilakukan koreksi dengan memperdalam cekungan menggunakan pahat sebagai tempat pertautan patela (sulcoplasty) (Gambar 2c). Pemendekan ligamen patela lateral, juga dikoreksi dengan pemotongan tendon dan mereposisi patela. Penjahitan dengan jahitan kessler grasping suture dan benang vicryl. Setelah patela direposisi, dilakukan penutupan kembali bagian otot dengan menggunakan catgut 3/0 dan bagian kulit menggunakan benang silk 3/0 (Gambar 2d). Setiap lapisan yang dijahit ditaburi dengan penicillin serbuk secukupnya.
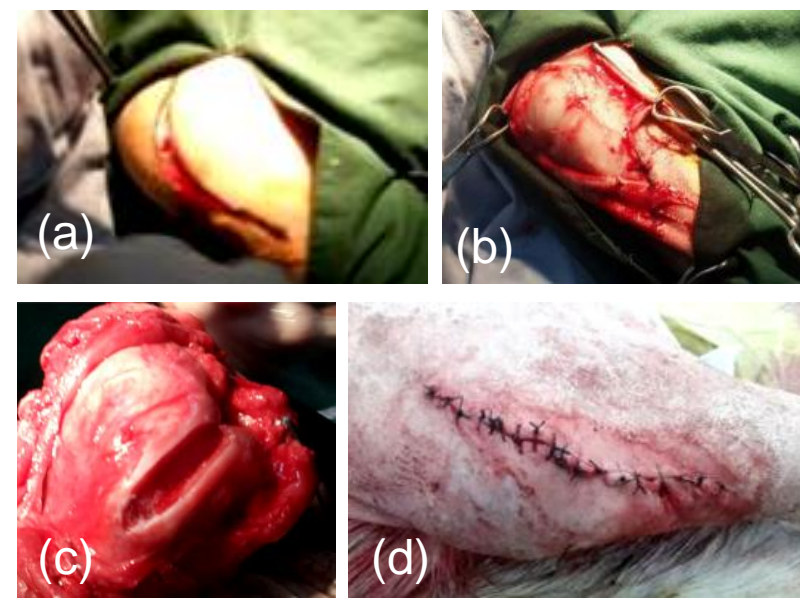

Gambar 2 Prosedur bedah kaki kambing yang mengalami luksasio tulang patela. (a) Penyayatan parapatellar, (b) Penguakan fascia,

(c) Sulkoplasti (d) Penjahitan pascabedah

\section{- HASIL DAN PEMBAHASAN}

Gambar radiografi memperlihatkan perubahan lokasi tulang patela yang berpindah posisi ke medial dan terlihat berada di belakang tulang femur (Gambar 1a). Persendian lutut kambing tidak dapat digerakkan dengan kondisi ini. Palpasi lutut tidak teraba unsur ligamen fiksator tulang patella saat pemeriksaan fisik. Teraba adanya penonjolan yang diduga tulang patela di bagian medial. Luksasio tulang patela ini sering ditemukan pada sapi dan kuda. Apabila terjadi perpindahan tulang patela maka hal dilakukan adalah mereposisi. Luksasion ke bagian medial tulang patela lebih sulit kembali ke posisi semula karena troklea tulang femoris di sisi medial yang lebih tinggi dibanding sisi lateral. Tindakan yang umum dilakukan untuk penanganan adalah dengan pemotongan ligamentum patela medial yang menarik os patela ke medial (Dyce et al. 2010).

Tulang patela berpindah ke lateral yang tampak pascapenyayatan kulit dan fascia. Tampak pula adanya perlekatan antara tulang patela, ligamenta, kapsula sendi, dan otot yang berada di lateral persendian. Hal ini karena trauma yang penrah terjadi pada waktu yang lampau. Osifikasi telah terjadi. Tampak pula adanya kelainan pada posisi tulang tibia yaitu lebih ke lateral, dilihat dari tuberositas tulang tibia yang tidak berada tepat dibawah troklea tulang femoris. Hal ini akibat tarikan ligamen dan luksasio dari tulang patela telah berlangsung lama sehingga arah pertumbuhan tulang mengalami kelainan.

Kambing pada kasus ini mungkin juga mengalami kelainan pertumbuhan troklea. Sudut troklea medial dengan sulkus dan troklea lateral sedikit curam. Kelainan ini dikoreksi dengan sulkoplasti. Sulcoplasty yaitu pembuatan sulkus troklea lebih dalam dengan cara memahat sulkus troklea, mengambil sedikit bagian subkondral dan menutup kembali dengan kartilago artikular, sehingga menghasilkan sulkus yang lebih dalam (Isaka et al. 2014 dan Harasen 2006b).

Proses penguakkan tulang patela dilakukan dengan memotong beberapa ligamentum, diduga ligamentum kolateral lateral ikut terpotong sehingga sehingga tulang tibia dapat direposisi dengan mudah. Beberapa tendo dan ligamen yang terpotong tidak dijahit karena sulit untuk dilakukan. Hal inilah menyebabkan kaki kambing lebih ke medial karena tarikan dari ligamentum kolateral medial dan tidak adanya ligamen yang menarik tulang tibia ke lateral.

Keadaaan hewan membaik pascabedah. Hal ini terlihat pada kaki kambing yang awalnya tidak mau ditumpukkan, perlahan mulai menumpukan kakinya. Citra radiografi menampakkan tulang patela berada di kranial tulang femur sehingga persendian lutut dapat bergerak dengan baik.

\section{- SIMPULAN}

Luksasio patela pada kambing dapat ditangani dengan pemotongan ligamen patela lateral dan sulcoplasty. Kambing menumpu dengan sedikit tertarik ke medial akibat pemotongan beberapa ligamentum di bagian lateral lutut.

\section{- INFORMASI PENULIS}

Penulis untuk Korespondensi

*DUR: ayiq.utari20@gmail.com, †ZHI: drhzoelvi@gmail.com Departemen Klinik Reproduksi dan Patologi, Fakultas Kedokteran Hewan, Institut Pertanian Bogor, Jalan Agatis Kampus IPB Dramaga Bogor 16680

\section{- PUSTAKA ACUAN}

Dyce KM, Sack WO, Wensing CJG. 2010. Textbook of Veterinary Anatomy. 4th Ed. Philadelpia (US): WB Saunders.

Harasen G. 2006a. Patellar luxation. CVJ. 47: 817-818.

Harasen G. 2006b. Patellar luxation: Pathogenesis and surgical correction. CVJ. 47: 1037-1039.

Isaka M, Befu M, Mastubara N, Ishikawa M, Arae Y, Tsuyama T, Doi A, Namba S. 2014. Corrective surgery for canine patellar luxation in 75 cases (107 limbs): Landmark for block recession. Vet Sci Dev. 4(5251):30-32.

Johnson AL, Probst CW, Decamp CE, Rosenstein DS, Hauptman JG, Weaver BT, Kern TL. 2001. Comparison of trochlear block recession and trochlear wedge recession for canine patellar luxation using a cadaver model. Vet Surg. 30:140-150. 